\title{
PRODUCTION OF CARBON FIBERS FROM CASTILLA'S CRUDE-OIL DEASPHALTED BOTTOMS
}

\author{
Gonzalo Leal*1 and Jhon-Iván Peñaloza ${ }^{2}$ \\ ${ }^{1}$ Ecopetrol - Instituto Colombiano del Petróleo, A.A. 4185 Bucaramanga, Santander, Colombia \\ ${ }^{2}$ Teinprecoop Ltda. \\ e-mail:gleal@ecopetrol.com.co
}

(Received 22 April 2002; Accepted 24 October 2002)

O

btaining raw materials for the manufacturing of carbon fibers from Castilla's crude-oil deasphalted bottoms was achieved through thermal treatments carried out in inert atmosphere, at temperatures ranging from $573 \mathrm{~K}$ to $673 \mathrm{~K}$. The deasphalted bottoms displayed isotropic characteristics. Deasphalted bottoms and thermally-treated fractions were characterized using elemental and thermo-gravimetric analyses; the softening point was also defined. The thermal treatment increases the $\mathrm{C} / \mathrm{H}$ ratio, which is reflected in the softening temperatures. Thermally-treated fractions showed excellent behavior in the threading process and the obtained fibers were stabilized through air-driven oxidation. Once the fibers were stabilized, they were carbonized in inert atmosphere, at $1073 \mathrm{~K}$ and $1273 \mathrm{~K}$. Results showed that when this raw material is processed, it has a performance rating of over $65 \%$, and produces compact, infusible structures that may be classified as general-use carbon fibers.

La obtención de precursores para la fabricación de fibras de carbono a partir de fondos de desasfaltado de crudo de Castilla se logró mediante tratamientos térmicos en una atmósfera inerte a temperatura entre $573 \mathrm{~K}$ y $673 \mathrm{~K}$, dichos fondos exhibieron características isotrópicas. Los fondos de desasfaltado y los fondos tratados térmicamente fueron caracterizados por análisis elemental, análisis termogravimétrico y se les determinó el punto de ablandamiento. El tratamiento térmico aumenta la relación $\mathrm{C} / \mathrm{H}$ lo cual se refleja en las temperaturas de ablandamiento. Los fondos tratados térmicamente presentaron excelente comportamiento en el proceso de hilado y las fibras obtenidas fueron estabilizadas por oxidación con aire, las fibras una vez estabilizadas se carbonizaron en atmósfera inerte a $1073 \mathrm{~K}$ y $1273 \mathrm{~K}$, encontrándose que este precursor al ser procesado tiene un rendimiento superior al $65 \%$, dando estructuras compactas, infusibles que pueden ser clasificadas como fibras de carbono de uso general.

Keywords: Carbon fibers, deasphalted bottoms, thermal treatment, pitch.

* To whom correspondence may be addressed 


\section{INTRODUCTION}

The so-called "new materials", which feature special physical-chemical properties, have speeded-up technological developments in the past few years. Carbon fibers are part of this set of new materials. They show special properties such as resistance to corrosion, chemical products and high temperatures at inert atmosphere; low friction and thermal expansion coefficients; and high electrical conductivity. Also, due to their high levels of compatibility and easy blending with diverse materials, such as carbon, polymers, plastics and cement, carbon fibers have generated a significant number of new, hybrid materials. These materials are basically applied to technologically advanced areas, such as the aerospace, high-competition sports and the automobile industries, among others (Alcañiz et al., 1998).

There are three different types of carbon fibers: The first type derives from poly-acrylonitrile (PAN), and is characterized by its capacity to resist high-tension strains; the second type, "anisotropic carbon fibers", is obtained from mesophase pitch, and features a high Young module. The third type consists of general-use fibers that are obtained from isotropic pitch, and features moderate mechanical properties (El Akrami et al., 2000). Pitch-derived carbon fibers have acceptable mechanical properties, although not as effective as those from PAN-derived carbon fibers (Singer, 1977).

The main application of PAN-derived carbon fibers involves the aeronautics sector, since these fibers have high rupture-resistance values. On the other hand, low manufacturing costs relating to pitch-derived carbon fibers allow for an extensive use of such fibers as structural material in the automotive industry. (Alcañiz et al., 1998). In general, the new carbon-fiber manufacturing technologies are focused on cost reduction; therefore, they intend to reduce the use of slow stabilization processes for PAN-based carbon fibers and to increase the rupture tension values for the pitch-based carbon fibers (Swaran et al., 1985).

Raw materials used in the manufacturing of pitchbased carbon fibers are usually byproducts from either oil refining or carbon gasification processes. Normally, pitches obtained from this type of fractions feature very low softening temperatures below $373 \mathrm{~K}$; there- fore, it is necessary to apply them a thermal treatment that may elevate their softening temperature (Dickakian, 1985). This result may be obtained through the withdrawal of low molecular weight compounds and by favoring polymerization reactions at temperatures ranging from $573 \mathrm{~K}$ to $673 \mathrm{~K}$, in inert atmosphere (Lewis, 1987).

The purpose of the thermal treatment is to transform deasphalted bottoms into a material that has the characteristics required to be threaded and that shows good reactivity levels during the stabilization phase (Sawran et al., 1985). If the raw material can be transformed into an anisotropic material by thermal treatment, then the fiber will have a high Young module, as well as high resistance to traction; on the other hand, if the resulting material is an isotropic one, then the fiber will have a low Young module and a moderate mechanical resistance (Osamu, 1999). The thermal treatment varies, depending on the type of raw material being used, although it will feature the following common aspects:

1. Removal of volatile materials at atmospheric pressure or through vacuuming.

2. Increase in molecule size through polymerization reactions.

3. Solvent-based removal of infusible materials that disable continuous threading.

4. Polymerization acceleration through the addition of catalysts.

Since deasphalted bottoms have high concentrations of asphaltenic structures, they feature a highly-aromatic character; therefore, their $\mathrm{C} / \mathrm{H}$ ratio is high. Furthermore, due to their low content of deasphalted oil (DAO), their softening point is not as low as that from other oil refining-based pitches. The characteristics mentioned above are the basic and key requirements for producing carbon fibers, and are the framework from which this study was conducted.

\section{MATERIALS AND METHODS}

Fractions used in this survey were obtained from deasphalting processes out of heavy hydrocarbons, at moderate pressures and temperatures. All tests performed 
on the raw material and the thermally-treated material were carried out at Ecopetrol-ICP laboratories.

\section{RAW MATERIAL}

Raw material used for all the tests performed was obtained from deasphalted bottoms taken from the Castilla heavy crude-oil. Prior to processing, the crude oil had an API of $13 @ 288,5 \mathrm{~K}$, and following the processing had an API of 20,5@288,5 K. Table 1 shows a typical characterization of these deasphalted bottoms.

Table 1. Typical characterization of Castilla's crude-oil deasphalted bottoms, prior to thermal treatment

\begin{tabular}{lclll|}
\hline \multicolumn{2}{l}{ Sara Analysis (\% weight) } & \multicolumn{2}{c|}{ Metals } \\
\hline Saturates & 9,53 & Nickel & $329 \mathrm{ppm}$ \\
\hline Aromatics & 13,90 & Vanadium & $803 \mathrm{ppm}$ \\
\hline Resins & 13,08 & Sulfur & $5,04 \%$ \\
\hline Asphaltenes & 63,49 & & \\
\hline
\end{tabular}

\section{Raw material treatment}

Fractions were thermally-treated in a stainless steel reactor. In order to guarantee an inert atmosphere nitrogen was bubbled into the reactor. Experiments were carried out at four different temperatures: $593 \mathrm{~K}, 623 \mathrm{~K}$, $643 \mathrm{~K}$, and $673 \mathrm{~K}$, that were measured using a K-type thermocouple. Samples obtained at these temperatures were named FTT320-2, FTT350-2, FTT370-2, and FTT400-2, respectively. For instance, FTT320-2 means thermally-treated fraction at $(593 \mathrm{~K})$ during 2 hours.

\section{Fiber Manufacturing}

\section{Threading}

Carbon fibers are manufactured through a threading process that transforms the molten pitch, at 40 to 60 degrees above the fraction's softening temperature, in solid filaments of a specific diameter. Threading itself is performed through an extrusion in which the molten fraction is passed through a single-hole nozzle (of 0,3 $\mathrm{mm}$ diameter, in this case), and the resulting fiber is hoarded by a bobbin that revolves at 1000 to $2000 \mathrm{rpm}$, from a distance of $20 \mathrm{~cm}$ to the mouthpiece as shown in Figure 1 (Otani, 1965). Variables to be considered for

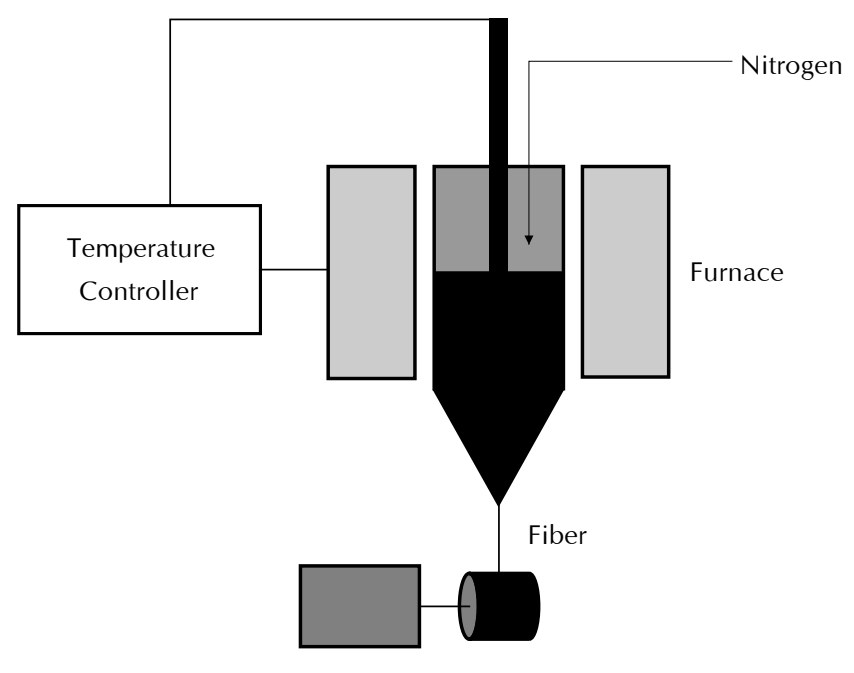

Figure 1. Pitch-threading equipment

the threading process include the following: viscosity of the molten phase, threading speed, distance from the nozzle to the rotor's axle, nozzle diameter, type of flow generated at the nozzle during the extrusion and, type of pitch.

\section{Stabilization}

Fibers obtained from thermally-treated fractions were stabilized through oxidation by injecting a flow of air into a reactor running at atmospheric pressure. Infusibilization was performed through a stabilization program in which fibers are subject to two heating stages: the first stage starts at the $413 \mathrm{~K}$ mark and has $1^{\circ} \mathrm{C} /$ min temperature increments during a ten-minute period. The second stage starts at the $600 \mathrm{~K}$ mark and has $2^{\circ} \mathrm{C} / \mathrm{min}$ temperature increments during a two-hour period.

\section{Carbonization}

Fibers were carbonized in two different tests, at $1073 \mathrm{~K}$ and $1273 \mathrm{~K}$. The carbonization program was performed with a single heating stage, featuring $5^{\circ} \mathrm{C} /$ min temperature increments. The stage lasted for 0,5 and 1 hour, for both cases. The process was carried out in an inert atmosphere, through the injection of nitrogen into the system.

\section{Characterization}

The softening points for deasphalted bottoms, before and after the thermal treatment, were defined through 
the "ring and ball" method, as per standard ASTM D 36-95. Optical properties of the thermally-treated fractions were observed through the use of a ReichertJung MeF-3 metallographic microscope. The C, H, N, $\mathrm{O}$ elemental analysis of these fractions was performed with a Perkin Elmer 2400 Serie II elemental analyzer, and the thermo-gravimetric analysis was performed with a Shimadzu TGA 50 thermo-gravimetric scale. Finally, the external morphology was observed on transversal sections of the carbon fibers, on goldcovered samples, through the use of a LEO 1450VP electronic sweep microscope.

\section{RESULTS AND DISCUSSION}

\section{General properties of the thermally-treated fractions}

Pre- and post-thermal treatment deasphalted bottoms were characterized through elemental analyses (softening point and $\mathrm{C} / \mathrm{H}$ ratio). Results of these analyses are included in Table 2, and show that thermal treatments are an effective method to increase deasphalted bottoms softening temperatures; this, in turn, supposes an increase in molecular size.

The $\mathrm{C} / \mathrm{H}$ ratio increases as thermal treatment temperatures rise, nearly reaching a $30 \%$ variation. This increment is associated to an increase in the molecular size, due to condensation-based polymerization reactions, as observed in Figure 2.

The experiments showed that all thermally-treated fractions presented two phases: one compact, shiny and dense phase, located at the lower part of the reactor;

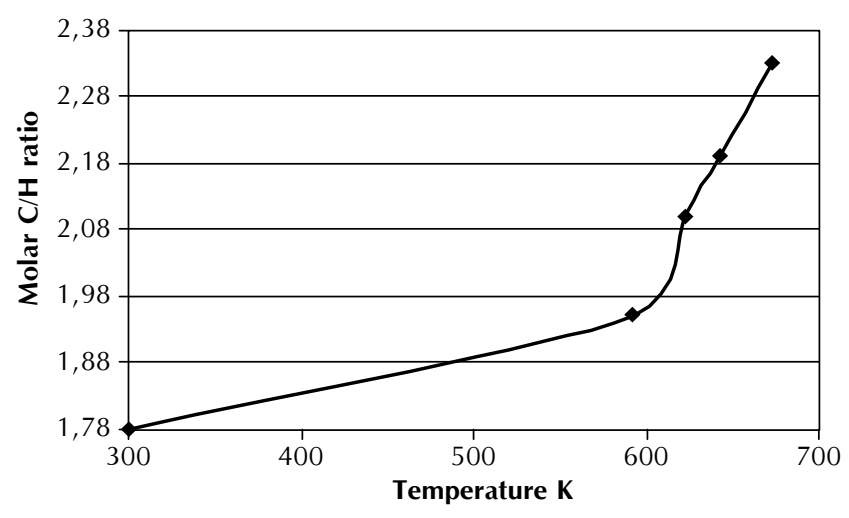

Figure 2. Variation of the $\mathrm{C} / \mathrm{H}$ ratio with the thermal treatment

and a porous, fragile and less dense phase, located at the upper part of the reactor. This phase increases as the treatment temperature increases, until it represents $60 \%$ of the thermally-treated fraction at $673 \mathrm{~K}$.

\section{Threading, Stabilization and Carbonization}

Results being displayed refer to the sample that showed the best behavior during the threading process. Thermal treatments performed upon deasphalted bottoms allowed for the production of isotropic pitches, which were threaded at a speed close to $100 \mathrm{~m} / \mathrm{min}$. Figure 3 shows a microphotography in which the isotropic character of the FTT320-2. The image shows that a continuous phase appears in the bottom of the structure without observing the formation of a second phase. This second phase could be characterized by the conformation of spheres or stiffness that would correspond to a phase of anisotropic character (Friel et al., 1980).

Table 2. Chemical analysis of Fractions

\begin{tabular}{|c|c|c|c|c|c|c|c|}
\hline \multirow{2}{*}{ Sample } & \multirow{2}{*}{$\begin{array}{l}\text { Softening Temperature } \\
\qquad\left({ }^{\circ} \mathrm{C}\right)\end{array}$} & \multicolumn{5}{|c|}{ Elemental Analysis (\% weight) } & \multirow{2}{*}{$\begin{array}{l}\text { Molar } \\
\mathrm{C} / \mathrm{H}\end{array}$} \\
\hline & & C & $\mathrm{H}$ & $\mathrm{N}$ & $\mathrm{s}$ & 0 & \\
\hline Fraction & 105 & 84,47 & 7,87 & 1,52 & 3,75 & 1,82 & 1,78 \\
\hline FTT320-2 & 226 & 84,00 & 7,19 & 4,34 & N.A. & N.A. & 1,95 \\
\hline FTT350-2 & 238 & 85,94 & 6,81 & 1,36 & N.A. & N.A. & 2,10 \\
\hline FTT370-2 & 260 & 85,99 & 6,54 & 1,43 & N.A. & N.A. & 2,19 \\
\hline FTT400-2 & 265 & 85,98 & 6,13 & 1,73 & N.A. & N.A. & 2,33 \\
\hline
\end{tabular}

N.A. Not available 


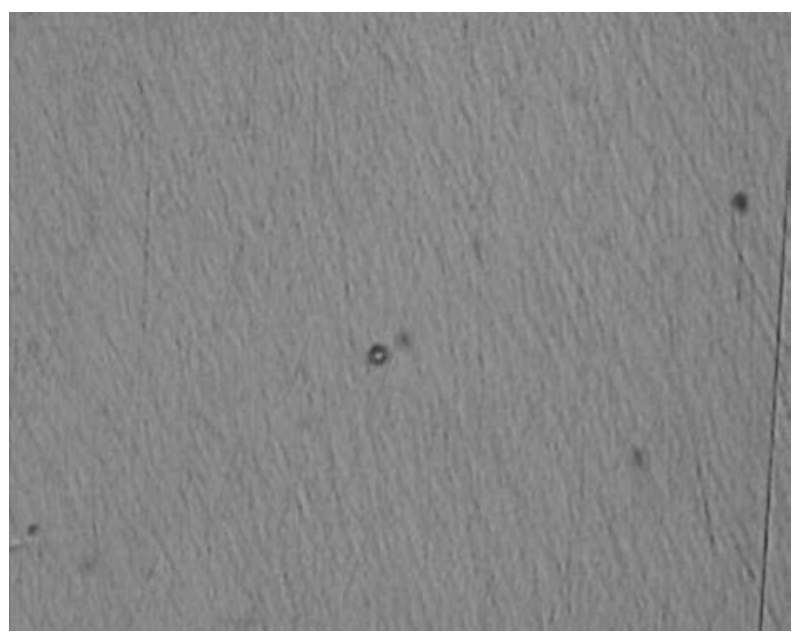

Figure 3. Polarized-light microphotography for sample FTT320-2

The stabilization process behavior depends on the chemical composition of the fractions, since a fraction having low aromaticity easily reacts to oxygen, incorporating it to its structure. The thermo-gravimetric analysis shows the behavior of the FTT320-2 fraction in oxidative atmosphere, as shown in Figure 4. The figure shows that approximately at $423 \mathrm{~K}$ oxygen starts to incorporate itself into the material's structure, and that decomposition starts at approximately $523 \mathrm{~K}$.

The elemental analysis included in Table 3 shows that stabilized fibers contain an oxygen percentage of nearly $20 \%$ in weight. This percentage certifies the success of the stabilization process and the ability of the pitch to incorporate oxygen into its structure. When these results are compared to those included in Table 2, it may be concluded that stabilized fibers incorporate nearly $19 \%$ of oxygen in weight during the stabilization process. This finding is as similarly reported by

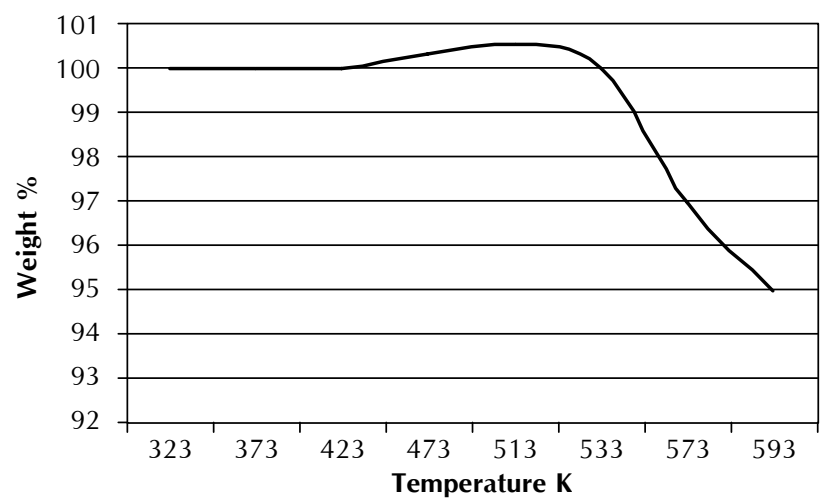

Figure 4. Thermo-gravimetric analysis of fraction FTT320-2

Park, S. H. et al., (2001). Infusibilized fibers obtained by this process are flexible, have better resistance to manipulation and do not combust when placed over direct flame. Infusibilization and carbonization processes significantly increase the $\mathrm{C} / \mathrm{H}$ ratio, as shown in Table 3 , proving the impact these two processes have on the fibers chemical structure.

The MEB microphotography in Figure 5 shows the appearance of fibers subject to a carbonization process, at a temperature of $1073 \mathrm{~K}$, for a one-hour period. The microphotography shows that the fiber surface is smooth and free of bumps; this allows us to state that the raw material does not include infusible materials, such as coke or metals. In Figure 6, it is also observed that the transversal section of the fibers is smooth, typical of isotropic pitches. Figure 7 shows a group of stabilized fibers that showed no adherence, thus suggesting that the stabilization process was carried out properly.

Table 3. Chemical composition of raw, stabilized and carbonized

fibers obtained from fraction FTT320-2

\begin{tabular}{|c|c|c|c|c|c|}
\hline \multirow{2}{*}{ Sample } & \multicolumn{4}{|c|}{ Elemental Analysis (\% weight) } & \multirow{2}{*}{ Molar $\mathrm{C} / \mathrm{H}$} \\
\hline & $\mathrm{C}$ & $\mathrm{H}$ & $\mathrm{N}$ & 0 & \\
\hline Raw threaded fiber & 84,00 & 7,19 & 4,34 & 1,96 & 1,95 \\
\hline Stabilized fiber & 64,30 & 2,68 & 1,40 & 20,12 & 3,99 \\
\hline Carbonized Fiber & 90,1 & 1,84 & 1,51 & 5,71 & 8,16 \\
\hline
\end{tabular}




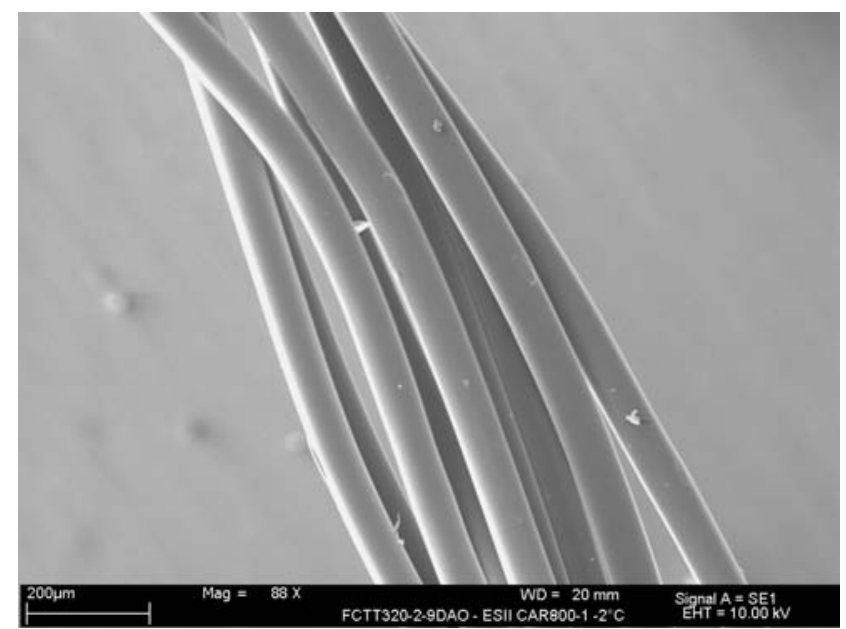

Figure 5. Micrography of a carbonized fiber (at $1073 \mathrm{~K}$, for one hour)

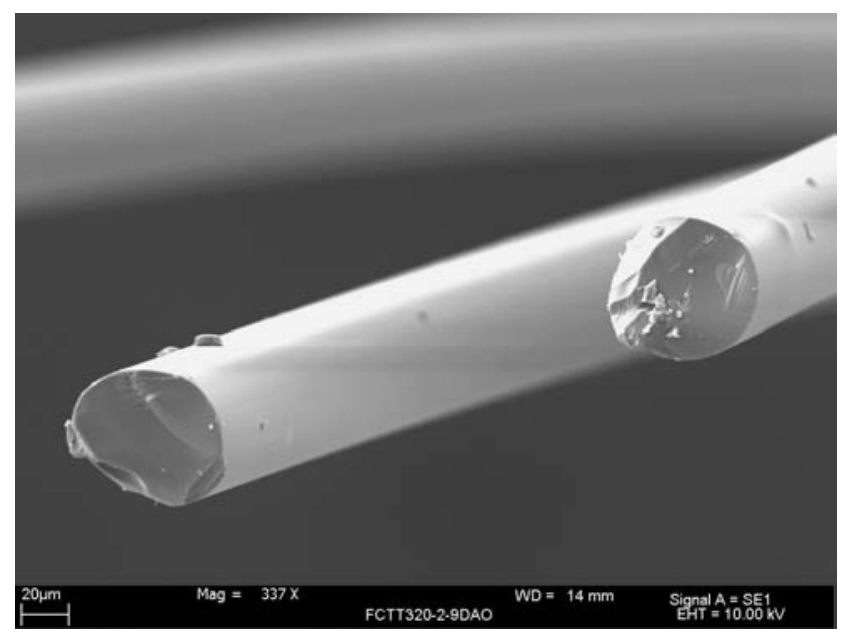

Figure 6. Micrography of a transversal section of a fiber obtained from fraction FTT320-2

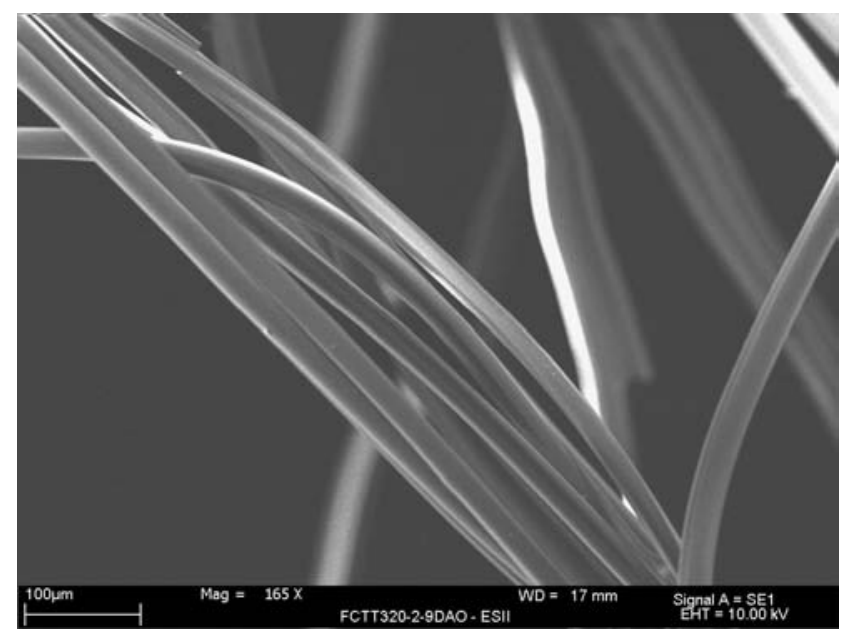

Figure 7. Micrography of stabilized fibers (FTT320-2) with no adherences

\section{CONCLUSIONS}

This research shows that when thermally treated at low temperatures and short processing periods, the Castilla's crude-oil deasphalted bottoms, may act as raw materials for the manufacturing of carbon fibers. These raw materials feature softening temperatures exceeding the $473 \mathrm{~K}$ and are easy to thread. Fibers obtained from these fractions were easily stabilized at $600 \mathrm{~K}$ and further carbonized at temperatures ranging from $1073 \mathrm{~K}$ to $1273 \mathrm{~K}$. The research shows that it is feasible to use deasphalted bottoms from the Castilla crude-oil in the manufacturing of general-use carbon fibers.

The results from this survey expanded the horizon of potential uses of the deasphalted bottoms from crude-oils and heavy hydrocarbons, developed by Ecopetrol - ICP. These discoveries are significantly attractive both technologically and the financially.

\section{BIBLIOGRAPHY}

Alcañiz, M. J., Cazorla, A. D. and Linares, S. A., 1998. "Fibras de carbón, preparación y aplicaciones". Publicaciones de la Universidad de Alicante, 27p.

Dickakian, G., 1985. "Aromatic pitch from asphaltene fractions”. U. S. Patent 4518483.

El Akrami, H. A., Yardim, M. F. and Ekinci, E., 2000. "Preparation and characterization of Raman-Dincer crude oil derived pitches for production of stabilized fibers". Fuel, 79: 497-504.

Friel, J. J., Mehta, S., Mitchell, G. D. and Karpinski J. M., 1980. "Direct observation of mesophase in coal". Fuel, 59: 610-615.

Lewis, I. C., 1987. “Chemistry of pitch carbonization”. Fuel, 66: 1527-1531.

Otani, S., 1965. "On the carbon fiber from the molten pyrolysis products". Carbon, 3: 31-38.

Osamu, K., 1999. "Process for manufacturing pitch-type carbon fiber". U. S. Patent No 5,968.435. 
Park, S. H., Yang, K. S. and Soh, S. Y., 2001. "Preparation of partial mesophase pitch-based carbon fiber from FCCDO”. Carbon Science, 2 (2): 99-104.

Singer, L. S., 1977. "High modulus, high strength fibers produced from mesophase pitch". U. S. Patent No 4005183.

Sawran, W. R., Turril, F. H., Newman, J. W. and Hall, N. W., 1985. "Process for manufacture of carbon fibers". U. S Patent No 4497789. 